\title{
Household exposure to violence and human rights violations in western Bangladesh (II): history of torture and other traumatic experience of violence and functional assessment of victims Shr-Jie Wang*1, Mohammad Akramul Haque², Saber-ud-Daula Masum², Shuvodwip Biswas ${ }^{3}$ and Jens Modvig ${ }^{1}$
}

Address: ${ }^{1}$ Rehabilitation and Research Centre for Torture Victims (RCT), Copenhagen, Denmark, ${ }^{2}$ Bangladesh Rehabilitation Centre for Trauma Victims (BRCT), Dhaka, Bangladesh and '3Dhaka University, Faculty of Social Sciences, Dhaka, Bangladesh

Email: Shr-Jie Wang* - sjw@rct.dk; Mohammad Akramul Haque - akramul2000@yahoo.com; Saber-ud-

Daula Masum - liton.masum@yahoo.com; Shuvodwip Biswas - shuvo85@yahoo.com; Jens Modvig - jmo@rct.dk

* Corresponding author

Published: 27 November 2009

BMC International Health and Human Rights 2009, 9:3 I doi:I0.| |86/|472-698X-9-3।
Received: I May 2009

Accepted: 27 November 2009

This article is available from: http://www.biomedcentral.com/|472-698X/9/3 |

(c) 2009 Wang et al; licensee BioMed Central Ltd.

This is an Open Access article distributed under the terms of the Creative Commons Attribution License (http://creativecommons.org/licenses/by/2.0), which permits unrestricted use, distribution, and reproduction in any medium, provided the original work is properly cited.

\begin{abstract}
Background: Organised crime and political violence (OPV) and human rights violations have marred Bangladesh history since 1971. Little is known about the consequences for the oppressed population. This study describes the patterns of OPV and human rights violations in a disturbed area of Bangladesh and assesses the physical, emotional and social functioning of victims.

Methods: A total of 236 of selected participants in a household survey in Meherpur district were recruited for a detailed study. Interviews and physical examinations were used to obtain information about history of torture and other cruel, inhuman or degrading treatment or punishment (TCIDTP), and about injuries, pain frequency and intensity. Handgrip strength and standing balance performance were measured. The "WHO-5 Well-being" scale was used to assess the subjective emotional well-being of study participants.

Results: The majority of the reported cases of TCIDTP occurred in 2000-2008, $51 \%$ of incidents occurred during winter; $32.0 \%$ between $20: 00$ and midnight. Police involvement was reported in $75 \%$ of cases. Incidents took place at victims' homes (46.7\%), or at the police station, military camp, in custody or in prison (21.9\%). Participants experienced I-IO TCIDTP methods and reported 0-6 injury locations on their bodies; $77.5 \%$ reported having at least two injuries. Less than half of the participants were able to stand on one leg for 30 seconds. Only $7.5 \%$ of males aged $25-44$ had handgrip strength in both hands exceeding average values for healthy people at the same age. Over $85 \%$ of participants scored low $(<13)$ on the 25-point "WHO-5 Well-being" scale. The number of years since the TCIDTP event, pain frequency, the need to quit a job to take care of an injured family member, political involvement, personal conflicts and the fear of neighbourhood violence strongly affected emotional well-being. Good emotional well-being correlated with increased political and social participation.
\end{abstract}

Conclusion: A detailed picture of characteristics of the victimisation is presented. The participants showed poor emotional well-being and reduced physical capacity. The results indicated that the simple and rapid method of assessment used here is a promising tool that could be used to monitor the quality and outcome of rehabilitation. 


\section{Background}

A clinical and functional assessment of the victims is essential when evaluating the effects of organised crime and political violence (OPV). Many studies have suggested that OPV has long-term psychological effects on an individual that persist throughout his or her lifespan. However, research documenting whether OPV results in the deterioration of physical and functional fitness, as well as social relationships, is limited [1-10].

Bangladesh has been a victim of a power struggle between its two major parties since it gained independence. The dominant parties have used armed groups and militias to fight for power $[11,12]$. The Cingranelli-Richards Human Rights Dataset shows that the people of Bangladesh have been terrorised especially since the 1990s, with increasing numbers of political imprisonments, torture, disappearances and extrajudicial executions [13]. The Political Terror Scale developed by Gibney et al. [14] measured the level of human rights violations in Bangladesh as 4 on a scale of 5 since late 1990 s, which indicated that the majority of population was affected.

The aims of the present study were to describe the history and pattern of OPV and human rights violations in a border region of Bangladesh, and to measure their consequences for the physical and emotional fitness and social functioning of the victims. It was a pilot study using a simple and rapid method of assessment, which could be further developed for use in countries with limited resources. Such a tool would be valuable for generating a baseline for monitoring the quality and outcome of rehabilitation services.

Our hypothesis in developing the method was that various personal factors, inter-personal relationships, and the extent of political involvement and social participation play a crucial role and interact with the current physical and emotional fitness and functional capacity in victims of OPV and human rights violations. Another hypothesis of the study was that reduced handgrip strength, and poor performance in standing balance measurements - both of which can be simply and inexpensively measured - would be related to having suffered from OPV and human rights violations.

\section{Methods}

Meherpur district, located within the Khulna division and bordered by India's West Bengal to the north, has an area of 716 square kilometres. It is the smallest district in Bangladesh, with an estimated population of 680,000 in 2008. Khulna division has been heavily affected by different forms of violence since the government launched two security operations: Operation Clean Heart in 2002 and Operation Spider Web in 2004.

\section{Study design and implementation}

A protocol was generated based on the World Health Organization (WHO) document "Guideline for conducting community surveys on injury and violence" [15], with a specific focus on OPV-related injury and mortality. The population-based study consisted of two parts: a household survey followed by OPV screening of selected participants in mobile clinics. In the first part of the populationbased study, we assessed household experiences of collective exposure to OPV and human rights violations as well as the burden on the families. Data were collected at the individual and family levels. Of the 1,101 households surveyed in Meherpur district from 23 February to 10 March, 2008 , over $80 \%$ reported exposure to more than two categories of OPV or human rights violations [16].

The second part of the study, reported in this paper, was a retrospective study in which a detailed OPV screening was carried out. The families that participated in the household survey and reported one or more of the following experiences were selected for OPV screening: 1) torture and other cruel, inhuman or degrading treatment or punishment (TCIDTP) ( $\mathrm{n}=343) ; 2)$ sexual harassment, molestation, rape or inserting blunt object into a genital organ and/or rectum $(n=9) ; 3)$ arrest and detention without warrant or order $(\mathrm{n}=317)$; or 4$)$ extrajudicial execution of family members $(n=78)$, perpetrated by members of law enforcement agency. This study used the definition of TCIDTP adopted by the United Nations Convention against Torture and Other Cruel, Inhuman or Degrading Treatment or Punishment. Altogether, 495 families were identified.

The selected families were given vouchers that outlined the aims and the process, including the offer of free medical examination and treatment at mobile clinics. We deployed four mobile clinics: one in Meherpur upazila, and one in Mujibnagar upazila on 12 March, 2008, and two in Gangni upazila on 13 March. The mobile clinics teams consisted of two coordinators, five medical doctors, four physiotherapists, two pharmacists from Dhaka and 12 social workers recruited from a Meherpur-based nongovernmental organisation (NGO) Manab Unnayan Kendra, and from Dhaka University.

The 356 people who volunteered to participate were taken in buses to one of the mobile clinics. At the entrance to the clinic the participants were screened again by one of the coordinators. Only people who were victims or secondary victims were included in the study. After the screening process, we excluded 120 participants who were either mentally ill or reported no experience of TCIDTP or others forms of OPV and human rights violations mentioned above. The excluded participants were not interviewed, but they were given a routine medical examination and 
treatment. Altogether, 236 victims were identified and recruited for the study. Their personal information was collected, including age, sex, education, religion, occupation and area of residence. The questionnaire was developed in English and translated into Bengali. After structured interviews, a physiotherapist or a specially trained interviewer measured height and weight, handgrip strength, and standing balance. A medical doctor performed a physical examination including a routine medical check-up, pulse measurement, and injury examination and provided a consultation. Injuries were recorded on a body map adapted from the Istanbul Protocol: international guidelines for the investigation and documentation of torture. Information about pain frequency and intensity was also obtained.

For the collection of data on body function, activity, participation and environmental factors a 14-point scale was constructed, based on the WHO International Classification of Functioning, Disability and Health [17] (body function: b130, b280, and b760; activity: a340, a450 and a740; participation: p930, p940, p950 and p798; environmental factors: e299, e320, e330 and e470). Subjective difficulties regarding mobility and body functioning were assessed on the following scale: "no", "yes" and "yes with some difficulty".

Physical fitness was measured by assessing muscle strength and equilibrium. Factors that can affect the outcome of these measurements, like weight, height and Body Mass Index (BMI), were also recorded. Under malnutrition conditions, muscular strength decreases before changes in anthropometric and laboratory parameters are noticeable [18-20]. Handgrip strength was measured by a Jamar $^{\circledR}$ hydraulic hand dynamometer according to the recommended procedure of the American Society of Hand Therapists[21]. We used the second handle setting for all participants, and scores were recorded in kilograms. During the measurement, participants were asked to adjust to the right position with their elbows flexed at 90 degrees, grip the dynamometer tightly and hold the grip for three seconds. Within-subject variations were considered and three measurements were taken for each hand. The average and the standard deviation (SD) of highest recorded grip strengths of each participant were calculated. The participants unable to undergo strength measurements because of upper limb deformities were excluded from these measurements.

The equilibrium function of the participants was measured by the standing balance test. The test measures the ability to stand on one leg, making use of all the sensory inputs that contribute to balance, i.e., the central vestibular system, vision, and proprioception (giving information to the brain about leg muscle position). Participants were excluded from testing if they were blind or had amputations or deformities of lower limbs. Participants were asked to stand barefoot on a flat floor on one foot with their eyes open. The physiotherapist/interviewer instructed the participants to adjust the standing position. A silent stopwatch was used to measure the time that each participant could balance on one foot without assistance; participants were asked to stop after 90 seconds.

The "WHO-5 Well-being" questionnaire was used to assess the subjective emotional well-being of study participants. The raw score is calculated by summating the figures of the five answers. Raw scores ranged from 0 to 25 . A score of 0 represents the worst possible, and 25 the best possible quality of life. A raw score under 13 is considered indicative of poor emotional well-being.

\section{Statistical analysis}

Data were entered and validated in Microsoft Access 2000 and Epi Info ${ }^{\mathrm{TM}} 6.04$ (CDC Atlanta, USA, 2001). For quality assurance, the data set was checked three times for typing discrepancies and transposition errors. All analyses were carried out using Stata software, version 9.2 (StataCorp LP, Texas, USA, 2003). The 5\% significance level ( $\mathrm{P}<$ $0.05)$ was used for all analyses. Explanatory variables for personal factors were age group, sex, residence, education, occupation, religion, political party affiliation and level of political and social participation. A generalised linear model was used to study the association between binary outcomes and explanatory variables, adjusted for the effects of other variables.

\section{Ethical evaluation}

The study is compliant with the Declaration of Helsinki and with Danish law. The Bangladesh NGO Bureau gave approval for the study. All of the participants gave informed consent. Treatment was free and severely traumatised cases were referred to the Bangladesh Rehabilitation Centre for Trauma Victims. The confidentiality and safety of participants is our primary concern. All the procedures used were designed to protect the privacy of the participants and the confidentiality of the information. It can be a risk for the oppressed population to participate in such a study; therefore, both the Bangladesh Rehabilitation Centre for Trauma Victims and the Task Force against Torture will be following up on the legal and health needs of victims once our study is completed. The sponsor had no role in the study design, data collection, analysis, and interpretation, and writing of the report.

\section{Results \\ Socio-demographic profile}

The sample population characteristics are presented in Tables 1 and 2. The mean age of 236 participants was 42.2 with a SD of 14 years (range 12-81) with no difference 
Table I: Social demographic profile of study participants, $\mathbf{n}=\mathbf{2 3 6}$

\begin{tabular}{|c|c|c|}
\hline Social demographic data & Variables & No. of victims (\%) \\
\hline \multirow[t]{4}{*}{ Upazila (sub-district) of Meherpur district } & Gangni upazila & $64(27.2)$ \\
\hline & Mujibnagar upazila & 89 (37.9) \\
\hline & Meherpur Sadar upazila & $82(34.7)$ \\
\hline & Missing & I $(0.4)$ \\
\hline \multirow[t]{8}{*}{ Education level } & None & $114(48.3)$ \\
\hline & Primary & $63(26.7)$ \\
\hline & Secondary & $37(15.7)$ \\
\hline & College or university & $10(4.2)$ \\
\hline & Post-graduate & $4(1.7)$ \\
\hline & Koran school & $\mathrm{I}(0.4)$ \\
\hline & Others & $6(2.5)$ \\
\hline & Missing & $\mathrm{I}(0.4)$ \\
\hline \multirow{3}{*}{ Religion } & Muslim & $229(97.0)$ \\
\hline & Hindu & $6(2.5)$ \\
\hline & Missing & $\mathrm{I}(0.4)$ \\
\hline \multirow{3}{*}{$\begin{array}{l}\text { Participation in a religious or spiritual activity within } 7 \text { days preceding the } \\
\text { survey }\end{array}$} & No & 89 (37.9) \\
\hline & Yes & $146(62.1)$ \\
\hline & Missing & I (0.4) \\
\hline \multirow[t]{7}{*}{ Occupation } & Not working & $6(2.5)$ \\
\hline & Household work & $48(20.3)$ \\
\hline & Agriculture, fishing, animal husbandry or hunting & $110(46.6)$ \\
\hline & Business & $30(12.7)$ \\
\hline & Service, journalist or teacher & $3(1.3)$ \\
\hline & Other & $38(16.1)$ \\
\hline & Missing & I (0.4) \\
\hline \multirow{4}{*}{ Involved in political party } & None & $138(58.5)$ \\
\hline & Awami League & $59(25.0)$ \\
\hline & Bangladesh Nationalist Party (BNP) & $29(12.3)$ \\
\hline & Jamaat-e-Islami Party & $10(4.2)$ \\
\hline \multirow[t]{5}{*}{ Level of political affiliation } & Supporter & $174(73.7)$ \\
\hline & Member & $34(14.4)$ \\
\hline & Activist & $5(2.1)$ \\
\hline & Leader & $2(0.8)$ \\
\hline & Missing & $21(8.9)$ \\
\hline \multirow[t]{2}{*}{ Often hold a meeting at home or attend a meeting in the community } & No & $212(89.8)$ \\
\hline & Yes & $24(10.2)$ \\
\hline \multirow[t]{2}{*}{ Have personal, financial or political conflict with other people } & No & $68(28.8)$ \\
\hline & Yes & $168(71.2)$ \\
\hline \multirow[t]{2}{*}{ Have ever participated in a demonstration, a strike or a human rights rally } & No & $13 \mid(55.5)$ \\
\hline & Yes & $105(44.5)$ \\
\hline \multirow[t]{2}{*}{ Have relative or friend working with law enforcement agency } & No & $136(57.6)$ \\
\hline & Yes & $100(42.4)$ \\
\hline \multirow[t]{2}{*}{ Have relative or friend involved in illegal activity } & No & $196(83.0)$ \\
\hline & Yes & $40(17.0)$ \\
\hline \multirow[t]{2}{*}{ Have good friends in whom you confide and who help you } & No & $136(57.6)$ \\
\hline & Yes & $100(42.4)$ \\
\hline
\end{tabular}


between men (78\%) and women (22\%). Only four participants were under 18 years old and 20 were over 65 years old. Nearly $50 \%$ of participants had no formal education at all.

\section{Political activity and social life}

The level of political involvement was considered because during the household survey, the affiliation of a family member to a political party was found to be a risk factor for victimisation [16]. Overall, 174 participants (80.9\%) were "party supporters" but 117 of them did not name any specific political party. There were $59(12.3 \%)$ who named the Awami League and 29 (12.3\%) the Bangladesh Nationalist Party (BNP). Only 34 participants (15.8\%) claimed to be members of a political party, five $(2.3 \%)$ were activists (two for the Awami League and three for the $\mathrm{BNP}$ ) and two (0.9\%) were local political leaders (one for the Awami League and the other for the BNP). There were 24 participants (10\%) who said they often held meetings at their homes or attended meetings in the community, and among them, 15 were party members and three were activists. Among the party supporters interviewed, 69.5\% supporters of the Awami League, 55\% of supporters of the BNP, and $60 \%$ of supporters of the Jamaat-e-Islami Party have participated in some type of demonstration, a strike or a human rights rally.

Over two-thirds of participants reported having personal, financial or political conflicts with other people. Over half of participants had been out to visit their friends within 7 days. When they were asked about their fear of violence in the community, $22.1 \%$ of participants said they had no fear of violence in the community, but $7.5 \%$ said they were often afraid, and 5.0\% that they were always afraid of violence.

\section{History of torture and other traumatic experience of violence}

The earliest cases of TCIDTP reported by the participants occurred as early as 1971 when the liberation war against Pakistan took place (Figure 1a). Only a few cases were reported during the first fifteen years of post-war Bangladesh from 1975 to 1990 . The number of reported TCIDTP cases remained small and stable in 1991-1995 but doubled in 1996-1999. Since 2000, the reported numbers have increased sharply. On average, 6.3 years (range $0-37$ ) passed between the time of TCIDTP and the present survey. Two of the participants who had been abused in 1971 were abused again in subsequent years.

The results demonstrated that 118 participants (51.1\%) were subjected to TCIDTP during the 4.5-month cool and dry winter season (mid October to February), while 76 participants $(32.9 \%)$ recalled the incident being during the 4-month hot and humid summer season (March to
June) and 37 participants (16.0\%) during the 3.5-month rainy monsoon season (July to mid October). Nearly one third of participants alleged that they were subjected to TCIDTP between 20:00 and midnight, which is the peak hour (Figure 1b). Events often occurred at the residence of the victims (46.7\%), and among them, 40\% occurred between 20:00 and midnight. Perpetration also occurred in closed environments, i.e., in a police station, in a military camp, in custody or in prison (21.9\%). Only $10.7 \%$ incidents occurred in open areas on streets or motorways (Figure 2a). The participants endured a total of 719 TCIDTP events.

The mean number of TCIDTP methods reported by each participant was 3.0 with a SD of 2.0. The maximum was 10 (reported by two members of Awami League). Around $20 \%$ of the participants $(n=46)$ were subjected to at least five methods. Among them, 19 were from the village called Shibpur and eight were from the village of Monakali; both of which are located along the BangladeshIndian border in Mujibnagar upazila. The five most frequently applied methods of TCIDTP were: 1) kicking; 2) beating with a blunt object; 3 ) falanga (beating the soles of the feet); and 4) threats to the family and mock execution; 5) other psychological torture (Table 3 ). In addition, sixteen participants (12 males and four females) experienced sexual harassment or forced sexual contact. One such participant was the local political leader of Awami League, who was also subjected to 10 methods of TCIDTP.

The police were the major perpetrators, being responsible for 183 cases $(75.3 \%)$, while 20 acts of TCIDTP $(8.2 \%)$ were committed by the Bangladesh Rifles (Bangladesh border force), 15 (6.2\%) by the Rapid Action Battalion (anti-crime and anti-terrorism elite force) and five $(2.1 \%$ ) by terrorists (Figure 2b). Among five victims of terrorists, two were also abused by the police and three were secondary victims. Among the 16 cases of sexual harassment or forced sexual contact, 12 involved the police, one involved the Rapid Action Battalion, one involved terrorists, one involved the Bangladesh Rifles, and one involved the Bangladesh Joint Force. The results showed that Meherpur Sadar police used torture methods more frequently than the Gangni and Mujibnagar police, i.e. they were responsible for 43 out of 65 falanga episodes, 11 out of 16 electric shock episodes and 10 of the 16 episodes of sexual harassment and forced sexual contact. It was also demonstrated in the household survey that more families living in Meherpur Sadar reported being subjected to TCIDTP [16]. Only 59 (25.1\%) participants had sought legal support in relation to their cases

\section{Health condition of victims}

The number of reported injury locations ranged from 0 to $6: 33.5 \%$ of participants reported having one injury loca- 
Table 2: Health indicators of study participants

\begin{tabular}{|c|c|c|c|}
\hline Health indicators & Male (n) & Female (n) & Total \\
\hline Sex & 183 & 52 & 235 \\
\hline Age group & Male (n) & Female (n) & Total (\%) \\
\hline $5-14$ & 0 & 1 & $\mathrm{I}(0.4)$ \\
\hline $15-24$ & 13 & 2 & $15(6.5)$ \\
\hline $25-34$ & 30 & 12 & $42(18.1)$ \\
\hline $35-44$ & 63 & 18 & $81(34.9)$ \\
\hline $45-54$ & 39 & 10 & $49(21.1)$ \\
\hline $55-64$ & 19 & 5 & $24(10.3)$ \\
\hline$\geq 65$ & 17 & 3 & $20(8.6)$ \\
\hline WHO-5 Well-being questionnaire & Male (n) & Female (n) & Total (\%) \\
\hline Score $\geq 13$ & 27 & 5 & $32(14.2)$ \\
\hline Score $<13$ (poor emotional well-being) & 149 & 44 & $194(85.4)$ \\
\hline Body size & Male & Female & \\
\hline Height (cm): mean (min-max) & $163.1(145-180)$ & $152.5(140-169)$ & \\
\hline Weight (kg): mean (min-max) & $55.0(35-82)$ & $51.6(26-78)$ & \\
\hline Body Mass Index (BMI: kg/m²) & Male (n) & Female (n) & Total (\%) \\
\hline $\mathrm{BMI}<16.5$ & 14 & 2 & $16(7.0)$ \\
\hline $16.5 \leq \mathrm{BM} \mid<18.5$ & 25 & 9 & $34(15.0)$ \\
\hline $18.5 \leq \mathrm{BM} \mid<23$ & 97 & 20 & $117(51.5)$ \\
\hline $23 \leq \mathrm{BMI}<27$ & 35 & 14 & $49(21.6)$ \\
\hline $\mathrm{BMI} \geq 27$ & 5 & 6 & II (4.8) \\
\hline Handgrip strength mean (kg) & Male & Female & \\
\hline Mean (min-max) for the right hand $(\mathrm{kg})$ & $30.6(0-55)$ & $23.4(|2-4|)$ & \\
\hline Mean (min-max) for the left hand $(\mathrm{kg})$ & $29.5(0-50)$ & $20.3(0-45)$ & \\
\hline Standing balance mean (seconds) & Male & Female & Total \\
\hline Mean $(95 \% \mathrm{Cl})$ for the right leg & $46.5(4 I .4-5 \mid .6)$ & $38.2(30.1-46.4)$ & $44.5(40.1-48.8)$ \\
\hline Mean $(95 \% \mathrm{Cl})$ for the left leg & $46.0(40.9-51.1)$ & $39.8(31.6-48.1)$ & $44.4(40.1-48.8)$ \\
\hline Standing balance performance & Male (n) & Female (n) & Total \\
\hline Right leg $>30$ seconds & 94 & 24 & 118 \\
\hline Right leg $\leq 30$ seconds & 82 & 28 & 110 \\
\hline Left leg $>30$ seconds & 95 & 25 & 120 \\
\hline Left leg $\leq 30$ seconds & 81 & 27 & 135 \\
\hline Pain intensity within 2 weeks & Male (n) & Female (n) & Total (\%) \\
\hline No pain & 3 & 0 & $3(1.3)$ \\
\hline Light pain & 17 & 8 & $25(11.0)$ \\
\hline Moderate pain & 133 & 37 & $170(74.9)$ \\
\hline Severe pain & 22 & 7 & $29(12.8)$ \\
\hline
\end{tabular}


Table 2: Health indicators of study participants (Continued)

\begin{tabular}{lccc}
\hline Pain frequency within 2 weeks & Male (n) & Female (n) & Total (\%) \\
\hline Constant pain (all the time) & 42 & 14 & $56(25.2)$ \\
Periodic pain (one or more times a week) & 85 & 26 & $111(50.0)$ \\
Occasional pain (less than once a week) & 44 & 11 & $55(24.8)$
\end{tabular}

tion, and 66.5\% reported having at least two (Table 4 ). The three most frequently injured areas were the lower back and abdomen (128 reported injuries), the legs (100 reported injuries), and the chest (58 reported injuries). The participants were at increasing risk of having leg or knee injury if they had been subjected to falanga (odds ratio $[\mathrm{OR}]=2.10,95 \% \mathrm{CI}=1.28-3.67, \mathrm{P}<0.01$ ) or to being kicked $(\mathrm{OR}=2.7,95 \% \mathrm{CI}=1.32-5.53, \mathrm{P}<0.01)$. There is an association between falanga and sole injury $(\mathrm{OR}=4.26,95 \% \mathrm{CI}=1.45-12.49, \mathrm{P}<0.01)$. Pain experience is shown in Table 2. During the two weeks preceding the survey, $25.2 \%$ of participants had experienced constant pain and $50.0 \%$ periodic pain.
Height and weight were measured for 228 participants (Table 2) (eight participants missed the measurement). BMI is defined as an individual's body weight divided by the square of his or her height. The mean BMI was 20.7 with a SD of 3.0 (range 13-29) for males and was 22.2 with a SD of 3.9 (range 12.9-31.2) for females. We used the cut-off values for being overweight $(23.0 \leq \mathrm{BMI}<27.0)$ and obese $\left(\mathrm{BMI} \geq 27.0 \mathrm{~kg} / \mathrm{m}^{2}\right)$ recommended for a Southeast Asian population by Singaporean and Indian researchers [22,23]. These values are somewhat lower than the global values. Around $22 \%$ of males and $21.6 \%$ of females were considered underweight (16.5 $\leq$ $\mathrm{BMI}<18.5)$ and malnourished $(\mathrm{BMI}<16.5)$. Only $8.5 \%$ of
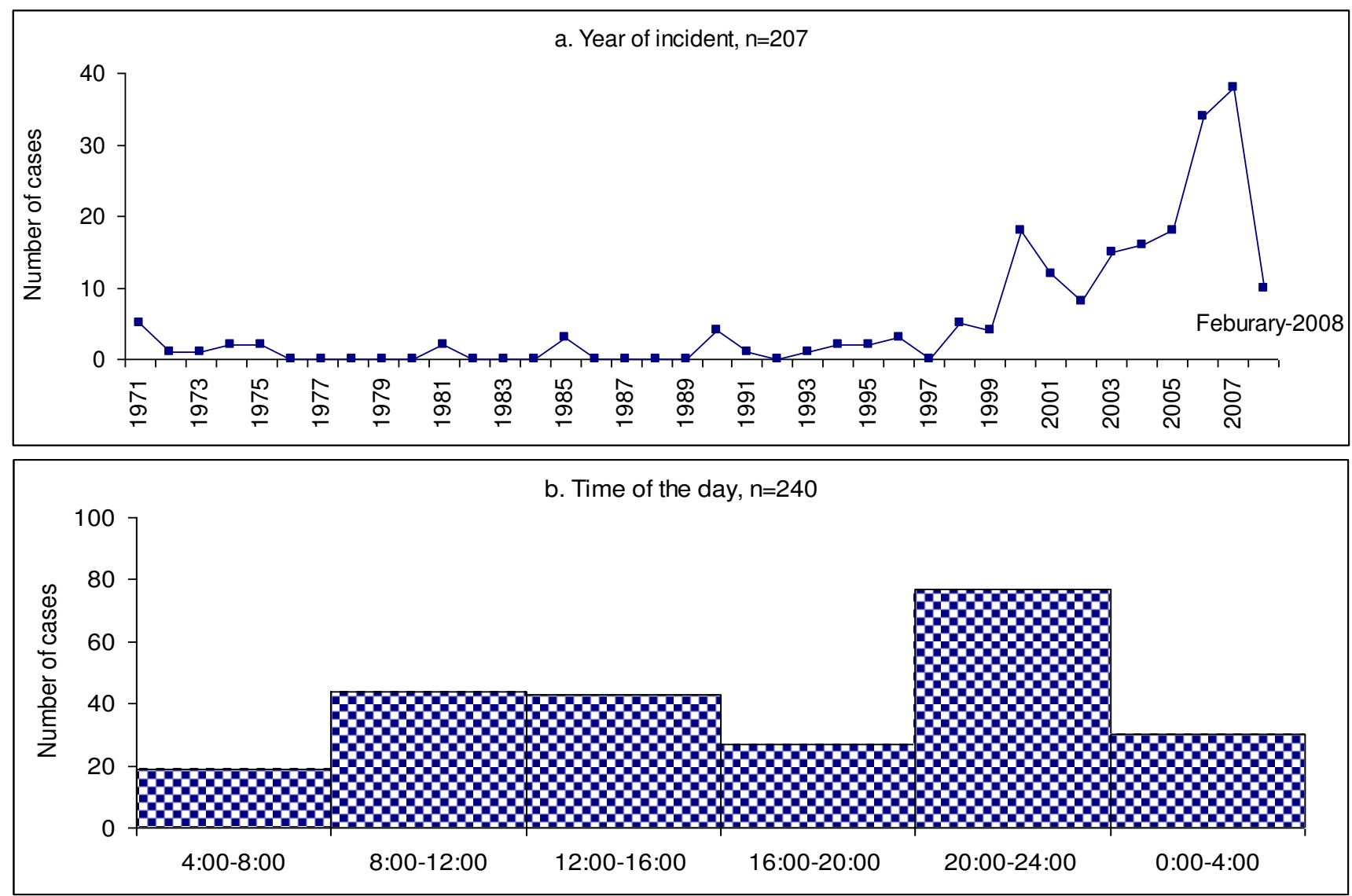

Figure I

Trend and patterns of incident reporting. 

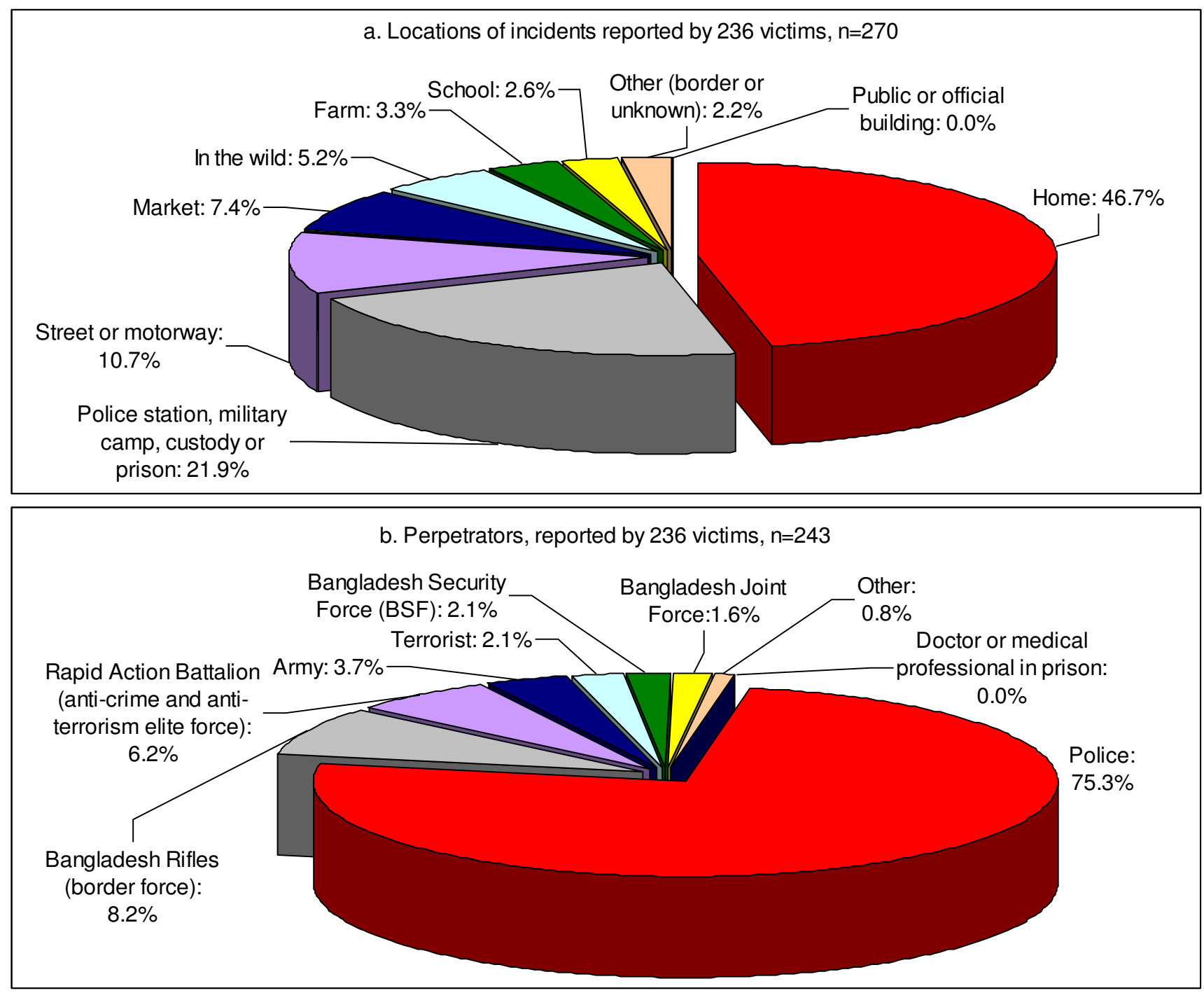

\section{Figure 2}

Locations and types of perpetrators.

males were overweight $(23.0 \leq \mathrm{BMI}<27.0)$, and no man was obese $(\mathrm{BMI} \geq 27)$, while $19.6 \%$ and of females were overweight and $2.0 \%$ obese. There are significant age and gender effects on BMI. Female participants generally have a higher BMI than males of the same age group (coef = $0.43,95 \% \mathrm{CI}=0.07-0.79, \mathrm{P}<0.05)$.

All participants were tested for their handgrip strength. For males, the mean strength was 30.6 with a SD of 10.7 $\mathrm{kg}$ for the right hand and 29.9 with a SD of $10.6 \mathrm{~kg}$ for the left hand. For females, the mean strength was 23.4 with a SD of $6.0 \mathrm{~kg}$ for the right hand and 20.3 with a SD of 7.1 $\mathrm{kg}$ for the left hand. For 147 out of 231 participants $(63.6 \%)$, right hand strength dominated left hand strength. We found that five participants had no strength in either hand, and two had no strength in their left hands. Lacking the national average for the general population in Bangladesh, we compared the mean handgrip strength of male participants aged 25-44 years old with that of a reference group of 100 healthy males aged 27-42 years in West Bengal: that of 50 office workers was $43 \mathrm{~kg}$ and that of 50 metal workers performing intensive manual labour was $41 \mathrm{~kg}$ [24]. The mean handgrip strength of 93 male participants in our study, aged 25-44 years, was 31.8 with a SD of $10.5 \mathrm{~kg}$ for the right hand and 30.0 with a SD of $10.9 \mathrm{~kg}$ for the left hand. Among them, eight (8.6\%) and $17(18.3 \%)$ had a handgrip strength equal to or above the mean handgrip strength of healthy male 
Table 3: Torture methods reported by the study participants

\begin{tabular}{llc}
\hline Rank & Torture method & No. of victims (\%) \\
\hline 1 & Being kicked & $17 \mid(23.8)$ \\
2 & Other psychological torture & $143(19.9)$ \\
3 & Being beaten or hit with a blunt object & $94(13.1)$ \\
4 & Falanga (beating on the soles of the feet) & $65(9.0)$ \\
5 & Threats to family, mock execution & $46(6.4)$ \\
6 & Strangulation & $43(6.0)$ \\
7 & Immersion in water or suffocation & $34(4.7)$ \\
8 & Being blindfolded & $30(4.2)$ \\
9 & Forced position & $24(3.3)$ \\
10 & Needle pricking & $23(3.2)$ \\
11 & Electric shock & $16(2.2)$ \\
12 & Sexual harassment, molestation, rape or inserting blunt object into a genital organ and/or rectum & $16(2.2)$ \\
13 & Other & $13(1.8)$ \\
14 & Burn & $6(0.8)$
\end{tabular}

office workers and the male brass metal workers. Only 7 of them had both handgrip strengths equal to or above 41 $\mathrm{kg}$.

In total, 229 participants were able to take the standing balance test. The mean duration of standing balance on the right foot was 44.5 seconds (95\% CI: $40.1-48.8$ ) and the mean duration for the left foot was 44.4 seconds (95\% CI: 40.1-48.8). The difference between the mean duration of standing balance between male and female participants is shown in Table 2. Only 102 participants (44.5\%) were able to stand on either foot for 30 seconds while 34 $(14.9 \%)$ could maintain their balance standing on one foot or the other for 30 seconds. A number of 93 participants $(40.6 \%)$ were unable to stand in a balanced position on either foot for 30 seconds.

Standing balance is negatively correlated with age over 55 years $(\mathrm{OR}=0.37,95 \% \mathrm{CI}$ : 0.21-0.65, $\mathrm{P}<0.001)$, but there is no association with gender. Obese people $(\mathrm{BMI} \geq 27)$ have more difficulty to maintain a standing balance (OR $=0.16,95 \% \mathrm{CI}=0.03-0.81, \mathrm{P}<0.05)$, as compared to

Table 4: Injury reporting by the study participants

\begin{tabular}{|c|c|}
\hline Numbers of reported injuries on the body map & No. of victims (\%) \\
\hline I & $76(33.5)$ \\
\hline 2 & $100(44.1)$ \\
\hline 3 & $32(14.1)$ \\
\hline 4 & $15(6.6)$ \\
\hline 5 & $2(0.9)$ \\
\hline 6 & $2(0.9)$ \\
\hline Missing & 9 \\
\hline Total & 236 \\
\hline Body mapping of injury & No. of injury (\%) \\
\hline Forehead & $9(2.0)$ \\
\hline Head & $19(4.2)$ \\
\hline Shoulder & $40(8.8)$ \\
\hline Chest & $58(12.8)$ \\
\hline Lower back and abdomen & $128(28.2)$ \\
\hline Arms & $23(5.1)$ \\
\hline Legs & $100(22.0)$ \\
\hline Ankles & $26(5.7)$ \\
\hline Toes & $2(0.4)$ \\
\hline Fingers of both hands & $10(2.2)$ \\
\hline Palms of both hands & $4(0.9)$ \\
\hline Total & 419 \\
\hline
\end{tabular}


people of normal size $(18.5 \leq \mathrm{BMI}<23.0)$ or underweight and malnourished people $(\mathrm{BMI}<18.5)$. After adjusting for age and BMI and the cluster effect of villages (prevalence of annual injury rate and violence-related injury was related to the level of exposure to OPV varied by villages) $[16]$ ), we found a strong negative association between standing balance and the number of injuries $(\mathrm{OR}=0.10$, $95 \% \mathrm{CI}=0.01-0.90, \mathrm{P}<0.05)$ and leg and knee injury $(\mathrm{OR}=0.57,95 \% \mathrm{CI}=0.35-0.96, \mathrm{P}<0.05)$.

One of the questions we asked participants was whether they had difficulty in walking to the other side of their village, or whether they needed help. The distances involved depended on which village a participant lived in. Odds ratios for good standing balance adjusted for age, BMI and the cluster effect of village were $2.94(95 \% \mathrm{CI}=1.33-6.52$, $\mathrm{P}<0.01$ ) for people who reported no difficulty in walking to another side of their village, and 2.67 (95\% CI-1.30$5.47, \mathrm{P}<0.01$ ) for people who needed assistance to walk this distance. The self-reported difficulty of walking thus correlates with the objective measurement on standing balance. No statistical association was found between standing balance and the number of years that had passed since the incidence of TCIDTP or between standing balance and the self-reported pain intensity and frequency during the two weeks preceding the survey, or to being subjected to falanga and being kicked.

Of the 225 participants who completed the "WHO-5 Well-being" questionnaire (one participant was missing), 194 (85.84\%) scored less than 13 (Table 2). A generalised linear model was used to evaluate the results and study the relationship between subjective emotional well-being, political involvement or social participation and personal factors (Table 5). Poor emotional well-being was not associated with being more than 55 years old, sex or education level. We did find a correlation between emotional wellbeing and pain frequency: people who had occasionally or periodically experienced pain within 2 weeks preceding the survey were at lower risk of a poor emotional wellbeing than people who suffered constant pain $(\mathrm{OR}=0.03$, $95 \% \mathrm{CI}=0.00-0.19, \mathrm{P}<0.001$ and $\mathrm{OR}=0.09,95 \% \mathrm{CI}=$ 0.01-0.82, $\mathrm{P}<0.05$, respectively). Also, participants were less likely to have poor emotional well-being if more years had passed since being subjected to TCIDTP $(\mathrm{OR}=0.82$, $95 \% \mathrm{CI}=0.72-0.93, \mathrm{P}<0.005)$ or if they were more involved in social or political activity: the odds ratio was 0.05 (95\% CI: 0.01-0.34, P < 0.005) for people who had participated in a demonstration, a strike or a human rights rally. A strong statistical difference is shown between different levels of political involvement: the activists are less likely to have poor emotional well-being $(\mathrm{OR}=0.03,95 \%$ $\mathrm{CI}=0.01-0.19, \mathrm{P}<0.001)$ than the general party supporters. Involvement in a conflict with other people (OR = 21.33, 95\% CI: 5.81-78.30, P $<0.001$ ), frequent fear of violence in the neighbourhood $(\mathrm{OR}=3.23,95 \% \mathrm{CI}$ : 1.64 6.36, $\mathrm{P}<0.001)$ and the experience of stopping work to take care of an injured family member (OR $=14.21,95 \%$ $\mathrm{CI}=1.31-154.00, \mathrm{P}<0.05)$ were all strongly associated with increasing vulnerability to poor levels of emotional well-being.

We categorised the victims into four different groups based on the methods of TCIDTP they were subjected to. The "basic level" consists of 1) beating with a stick or a blunt object, 2) blindfolding and 3) kicking. The "basic + psychological torture level" indicates the "basic level" plus psychological torture. Victims who were subjected to torture at a "basic level" and in addition to any severe torture method were grouped as "basic + severe torture cases". The victims who were subjected to torture at a "basic level" and in addition to psychological torture plus any of the severe torture methods were grouped as "all". Out of 224 victims (two participants missed reporting any TCIDTP method), $46(20.5 \%)$ had been subjected to the "basic level" of TCIDTP while 41 (18.3\%) and underwent "basic + psychological torture" and 35 (18.3\%) underwent "basic + severe torture". A further 102 of the 224 victims (45.4\%) were subjected to "all" TCIDTP methods. No statistical association was found between the types/ levels of TCIDTP methods victims were subjected to and either their physical performance (hand grip strength and standing balance), or their emotional well-being.

\section{Discussion}

The present study provides a detailed clinical and functional assessment of a sample of 236 participants in a border area in Bangladesh who reported during a household survey [16] that they had been subjected to OPV and human rights violations during the past 38 years. We used a combination of physical examination and simple physical tests, a questionnaire and interviews to record the history and present situation of the participants and to assess their social and physical functioning and well-being.

The participants' reports did not only provide information about individuals, but about the wider history of OPV and human rights violations. The earliest reported incident in our study was in 1971. The first arrest reported in the patient records of the Bangladesh Rehabilitation Centre for Trauma Victims was also in 1971. There may have been incidents before the liberation war, but there is some doubt as to whether the victims are still alive. In our study, only a few incidents were reported from 1971 to 1990 . From 1991 to 1995 there were still relatively few, but the frequency doubled in 1996-1999, and since 2000, the reported numbers have increased sharply. The years 1971, 1990-91, 1996-97 and 2000-01 are crucial in the history of OPV and human rights violations in the whole of Bangladesh. In these years, there was a high level of political 
Table 5: Standing balance performance, emotional well-being and its association with personal factors and health condition

\begin{tabular}{|c|c|c|c|c|}
\hline Variables (Both legs stand more than 30 seconds) & No & Yes & OR (95\% Cl) & P value \\
\hline BMI $<16.5$ & 8 & 8 & 1 & - \\
\hline $16.5 \leq \mathrm{BMI}<18.5$ & 21 & 13 & $0.51(0.19-1.36)$ & 0.180 \\
\hline $18.5 \leq \mathrm{BMI}<23$ & 57 & 59 & $0.7 I(0.29-1.75)$ & 0.461 \\
\hline $23 \leq \mathrm{BMI}<27$ & 32 & 17 & $0.45(0.16-1.25)$ & 0.125 \\
\hline $\mathrm{BMI} \geq 27$ & 9 & 2 & $0.17(0.03-0.81)$ & $<0.05$ \\
\hline Male & 95 & 81 & 1 & - \\
\hline Female & 31 & 21 & $0.96(0.35-2.60)$ & 0.930 \\
\hline Age $<55$ & 95 & 88 & 1 & - \\
\hline Age $\geq 55$ & 30 & 12 & $0.37(0.21-0.65)$ & $<0.001$ \\
\hline Injury mapping (adjusted for age and BMI) & No & Yes & OR $(95 \% \mathrm{Cl})$ & $P$ value \\
\hline 0 injury & 3 & 6 & 1 & - \\
\hline $\mathrm{I}-2$ injuries & 89 & 80 & $0.21(0.02-2.20)$ & 0.19 \\
\hline$\geq 3$ injuries & 35 & 16 & $0.10(0.01-0.90)$ & $<0.05$ \\
\hline Without leg and knee injury & 66 & 66 & 1 & - \\
\hline With leg and knee injury & 61 & 36 & $0.57(0.35-0.96)$ & $<0.05$ \\
\hline Can not walk to another side of village & 34 & 11 & 1 & - \\
\hline Able to walk to another side of village without assistance & 51 & 51 & $2.94(1.33-6.52)$ & $<0.005$ \\
\hline Need assistance to walk to another side of village & 38 & 35 & $2.67(1.30-5.47)$ & $<0.005$ \\
\hline Pain (adjusted for age and BMI) & No & Yes & OR $(95 \% \mathrm{Cl})$ & $P$ value \\
\hline No pain & 1 & 2 & 1 & - \\
\hline Light pain & 14 & 11 & $0.31(0.01-15.50)$ & 0.56 \\
\hline Moderate pain & 105 & 65 & $0.22(0.00-10.19)$ & 0.44 \\
\hline Severe pain & 23 & 7 & $0.12(0.00-6.24)$ & 0.29 \\
\hline Constant pain (all the time) & 43 & 14 & 1 & - \\
\hline Periodic pain (one or more times a week) & 63 & 48 & $1.84(0.76-4.46)$ & 0.18 \\
\hline Occasional pain (less frequent than once a week) & 35 & 20 & $1.24(0.49-3.15)$ & 0.65 \\
\hline Years passed since TCIDTP incident (adjusted for age and BMI) & No & Yes & OR $(95 \% \mathrm{Cl})$ & $P$ value \\
\hline 0 & 6 & 4 & I & - \\
\hline I-2 years & 39 & 32 & 0.92 & 0.902 \\
\hline $3-5$ years & 25 & 22 & 1.28 & 0.732 \\
\hline $6-10$ years & 27 & 19 & 0.70 & 0.672 \\
\hline$>10$ years & 14 & 13 & 2.16 & 0.415 \\
\hline Variables (WHO-5 Well-being <13, poor emotional well-being) & & & OR $(95 \% \mathrm{CI})$ & $P$ value \\
\hline Political party member vs. general party supporter & & & $0.53(0.77-3.77)$ & 0.522 \\
\hline Activist vs. general party supporter & & & $0.03(0.01-0.19)$ & $<0.001$ \\
\hline Often attend meeting or hold meeting at home & & & $1.27(0.12-13.04)$ & 0.839 \\
\hline Have participated in demonstration, a strike or a human rights rally & & & $0.05(0.01-0.34)$ & $<0.005$ \\
\hline Have conflict with other people & & & $21.33(5.81-78.30)$ & $<0.001$ \\
\hline Number of years passed since TCIDTP incident & & & $0.82(0.72-0.93)$ & $<0.005$ \\
\hline Periodic pain vs. constant pain & & & $0.09(0.01-0.82)$ & $<0.05$ \\
\hline Occasional pain vs. constant pain & & & $0.03(0.00-0.19)$ & $<0.001$ \\
\hline Frequency of fear of violence in the community & & & $3.23(1.64-6.36)$ & $<0.001$ \\
\hline Stop working to take care of an injured family member for a period & & & $14.21(13.1-154.00)$ & $<0.05$ \\
\hline Education level & & & $0.88(0.62-1.23)$ & 0.444 \\
\hline Age $\geq 55$ & & & $3.40(0.56-20.62$ & 0.183 \\
\hline
\end{tabular}


tension and violence; this pattern is shown in our study and also reported by other institutions $[11,12,25,26]$. There were general elections in Bangladesh in 1991, 1996 and 2001, which were wrecked by pre and post-election violence. Over $80 \%$ of the participants in our study claimed to be "party supporters" but only a few of them revealed which political party they supported. Therefore we were unable to do further analysis to test our hypothesis that the supporters of an opposition party were more likely to be victimised as the political tension increased sharply in the year of general elections.

Human rights violations including the use of TCIDTP have intensified in the last five years in Meherpur district since Operation Spider Web was launched, and violence and crime have been aggravated. Since 2006, the enforcement of strict emergency regulations by a care-taker government has increased the brutality of violent confrontations.

The results also showed a seasonal pattern. The number of reported cases was three times higher during the winter season than during the rainy season. It is clear that the police and the military are hampered by the flooding and uncomfortable conditions during the rainy season.

From the results of our study it appeared that the police were the major perpetrators. Individuals could be attacked by armed militias associated with party politics, but such incidents were not reported here. Such individuals were not likely to present in the mobile clinic, because the recruitment criteria were primary or secondary victims subjected to any of four categories of OPV and human rights violations perpetrated by the members of law enforcement agency. Mitchell (2004) pointed out that the degree of political control that the political authorities exercise over a law enforcement agency varies across time and political system. It is plausible that if individuals in a law enforcement agency have goals independent of those of the authority, or have private interests, this may influences the choice, level and method of violence [27].

The survey provided detailed information about the methods used by the perpetrators. A previous study in Sri Lanka suggested that perpetrators generally use readily available materials as TCIDTP instruments [28]. Methods gain popularity if they cost nothing, are available anywhere at any time, can achieve maximum effect, and rarely leave clear evidence, e.g., falanga (beating the soles of the feet) or being kicked.

Forced sexual contact and sexual abuse are also frequently-used forms of torture. It was reported that all of the female refugees and one-third of the male refugees from Bangladesh examined at the Centre for Torture and
Trauma Survivors in Stockholm alleged that they had been raped [29]. In our study, few participants reported that they had been sexually harassed, abused or raped. However, owing to the social stigma involved, victims may not admit to being raped or sexually abused by members of a law enforcement agency unless they are far away from the perpetrators and from their own community. This helps to explain the low number of cases identified in our study. Among them, there were more males $(n=12)$ than females $(n=4)$. Rape and sexual abuse of males is not rare: it was shown that $22 \%$ of inmates in Nebraska, USA in 1996 [30] and 21\% Tamil detainees in Sri Lanka reported at least one episode of forced sexual contact [31]. Up to now, the epidemic character of using male rape and sexual abuse as a weapon in the conflict setting [32-34] and in closed environments, i.e. detention and prison, has been neglected by the authorities. A low level of control of corruption in the administration is likely to provide the members of law enforcement agency with a wealth of opportunities for hidden actions including the perpetration of sexual violence [35]. It is also plausible that in the society in which homosexuality is not approved of, the setting of detention and prison allows the individuals of law enforcement agency who seek for particular sexual interest to conceal their actions.

Very little is known about the physical and emotional consequences and social functioning of an oppressed population experiencing collective exposure to OPV and human rights violations. The rehabilitation of TCIDTP victims has been mainly based on clinical experiences seen from an illness perspective. For people who continue to live in their communities, it is most important that they should be able to maintain daily life after being traumatised. A basic level of muscle strength and physical mobility is required, simply to be able to cope with the activities of daily life.

In our study we assessed muscular function by measuring handgrip strength, which is required in many daily activities in a rural area. Hand dynamometer testing is recommended to determine the loss of handgrip strength [3638]. This method is widely used for outcome documentation after injuries of the upper extremities [39], as a functional index of nutritional status, and for determination of impairment [40]. Our study was the first to use the method to investigate loss of muscle strength in a survey of a population exposed to massive OPV and human rights violations. Because standard normative values for healthy adults for all age groups in Bangladesh or in South Asia are not available, we used values for young and middle aged male adults in West Bengal [24]. Our survey participants showed lower muscle strength in their dominant hands. However, we did not determine whether the reduced muscle strength was the consequence of the trau- 
matic experience, and a further study with a control group is needed.

Our study was also the first to assess standing balance performance in an oppressed population. Impaired lower extremity performance is associated with reduced physical activity levels, which may contribute to subsequent disability in elderly persons [41,42]. Standing balance is related to physical fitness and consequently to social life $[43,44]$. Many participants reported lower back, leg and knee injuries, which can affect standing balance. We found evidence that there was an association between objective measurements of standing balance performance and self-reported walking performance, which also indicated the reliability of subjective difficulty measured and reported by the victims. The standing balance test is a simple rapid assessment tool and could be considered as an instrument to be used routinely in the initial functional assessment procedure of victims of torture or other forms of violence. We recommend conducting a comprehensive balance and mobility assessment when standing balance performance of a victim is poor even after adjustment for age and BMI.

The measures used to test muscle strength and physical mobility in our survey are rapid and inexpensive, so they are appropriate for use in countries with limited resources. Such tests can be used to produce essential information for purposes of diagnosis and prognosis, as well as for prevention and rehabilitation. The results could also contribute to quantifying the economic burden in terms of disability and manpower lost due to OPV and human rights violations, and their association with poverty in a country such as Bangladesh.

A person's functioning does not only depend on muscular strength but also on emotional factors. We used the brief questionnaire "WHO-5 Well-being" to estimate the percentage of victims with poor subjective emotional wellbeing, and to examine the association of subjective emotional well-being with social participation. Emotional, physical, and social vulnerability as a consequence of being abused is related to the development of post-trauma stress disorder and other mental disorders. The inter-personal and inter-family conflicts are high in the study area. In order to develop programmes which can help to reduce the damage to emotional health and to prevent its harsher effect on mental health, we need to understand what factors may empower victims to cope with their vulnerability.

One factor that we considered was active participation in political or social movements. The effects of political and social participation on well-being are complex. On the one hand, in the household survey we found that if a fam- ily member was affiliated to a political party or participated in a demonstration, a strike or a human rights rally, this was a risk factor for victimisation [16]. On the other hand, the present study found that participation in a political or social movement was linked to improved emotional well-being; it could strengthen people's selfconfidence and restore their interest in social justice and the environment. Many trauma victims have a poor selfimage and low self-esteem. Organising or taking part in a demonstration, a strike or a human rights rally allows participants to share and release their feelings of stress and frustration, to express their anger in a collective voice, and to bond with others and create alliances. Participation can empower the victims and thus improve their emotional well-being. These interactions demonstrate the complexity of the factors that determine emotional well-being; on the one hand, the patterns of political or social participation affect the emotional well-being of trauma victims, but, on the other hand, their emotional well-being also determines the personal, social, and behavioural competence in relationships and the capacity to deal constructively with a challenging or difficult situation $[45,46]$.

\section{Limitations and strengths}

Our findings concerning perpetrators and years of perpetrations were consistent with reports from other international institutions $[11,12,25,26]$ and also from a local human rights organisation, Odhikar. A medical examination that found traces of injury is also a validation of the oral reports. We used simple physical tests to confirm the reliability of subjective difficulty in walking reported by the study participants.

One limitation was that owing to logistical and political constraints, we did not recruit people without prior TCIDTP experience as a healthy control group while taking into account neighbourhood effect on OPV or human rights violations. In addition, there was inevitably some risk of bias in the recruitment of the study group. The health-seeking behaviour of the individuals concerned is one possible source of bias. We do not know why some who had vouchers decided not to come to the mobile clinic. Some of them may have been so severely depressed that they lacked any motivation to come - and others may have seen no need to interrupt their work to come to the clinic. It is also possible that there was some bias because a few participants exaggerated their injuries and pain experiences in order to receive more treatment. Memory bias does exist, but the main increase in OPV and human rights violations in this area took place within the last 10 years, and ten-year recall is considered reliable [47].

We had hoped to use the results as a baseline for a largescale intervention in this community, and to repeat the measurements afterwards to monitor the quality and out- 
come of rehabilitation. We had already developed plans for various interventions including setting up a platform, Victim Association, where the survivors can talk about their fears and stigmas and re-construct their self-images, and which will also serve as a place for social participation and political empowerment. The members should assist the Victim Association to raise the community awareness and spread knowledge about human rights by organising various community activities. Unfortunately, these cannot immediately be realised for unexpected reasons

\section{Conclusion}

This study presents trends and patterns of OPV and human rights violations in the Meherpur district. Generally, the oppressed population showed poor emotional well-being and a reduced level of physical fitness. Among study participants, good subjective emotional well-being correlated with increased political and social participation. To monitor the quality and outcome of rehabilitation, the simple and rapid methods used here could be developed into a valuable tool for initial assessment. Further studies are also needed to establish reference values in the general population and oppressed populations within this complex setting.

\section{List of abbreviations}

BNP: Bangladesh Nationalist Party; BRCT: Bangladesh Rehabilitation Centre for Trauma Victims; BMI: Body Mass Index; OPV: organised crime and political violence; OR: odds ratio; NGO: non-governmental organisation; RCT: Rehabilitation and Research Centre for Torture Victims; SD: standard deviation; TCIDTP: torture and other cruel, inhuman or degrading treatment or punishment; WHO: World Health Organization.

\section{Competing interests}

The authors declare that they have no competing interests.

\section{Authors' contributions}

SJW participated in the design of the study, conducted the field work, analysed and interpreted data and drafted the manuscript. MAH, SDM and SB participated in the coordination in the field, managed and supervised the data collection. JM participated in the conception of the work, helped to draft the manuscript and revised it critically. All the authors have read and approved the final version of the manuscript.

\section{Acknowledgements}

The study was funded by the Novo Nordisk Research Foundation. We thank Akram H. Chowdhury and the local NGO: Manab Unnayan Kendra for their coordination and logistic support. Special thanks go to the physiotherapists Karen Prip and Anette Klahr as well as Per-Erik Isberg, Department of Statistics, Lund University, Sweden for the advice on data analysis. We acknowledge the help of Jennifer Jenkins, David Chung and Andrei Chirokolava in the editing of the manuscript.

\section{References}

I. Mirzaei S, Knoll P, Lipp RW, Wenzel T, Koriska K, Kohn H: Bone scintigraphy in screening of torture survivors. Lancet 1998 , 352(9132):949-95I.

2. Nice DS, Garland CF, Hilton SM, Baggett JC, Mitchell RE: Long-term health outcomes and medical effects of torture among US Navy prisoners of war in Vietnam. JAMA 1996, 276(5):375-38I.

3. Mollica RF, Donelan K, Tor S, Lavelle J, Elias C, Frankel M, Blendon RJ: The effect of trauma and confinement on functional health and mental health status of Cambodians living in ThailandCambodia border camps. JAMA 1993, 270(5):581-586.

4. Goldfeld AE, Mollica RF, Pesavento BH, Faraone SV: The physical and psychological sequelae of torture. Symptomatology and diagnosis. JAMA 1988, 259( I 8):2725-2729.

5. Chotani HA, Razzak JA, Luby SP: Patterns of violence in Karachi, Pakistan. Inj Prev 2002, 8(I):57-59.

6. Rasmussen A, Rosenfeld B, Reeves K, Keller AS: The effects of torture-related injuries on long-term psychological distress in a Punjabi Sikh sample. J Abnorm Psychol 2007, I I 6(4):734-740.

7. Moreno A, Peel M: Posttraumatic seizures in survivors of torture: manifestations, diagnosis, and treatment. J Immigr Health 2004, 6(4): $179-186$.

8. Bradley L, Tawfiq N: The physical and psychological effects of torture in Kurds seeking asylum in the United Kingdom. Torture 2006, I6(I):41-47.

9. Hougen HP: Physical and psychological sequelae to torture. A controlled clinical study of exiled asylum applicants. Forensic Sci Int 1988, 39(I):5-II.

10. Missliwetz J, Denk W: [Maltreatment by police officers?]. Arch Kriminol 1991, 187(2): I- I2.

II. Human Rights Watch: Judge, jury, and executioner: torture and extrajudicial killings by Bangladesh's elite security force. 2006, I 8( I 6 c):79.

12. Asian Legal Resource Center and Asian Human Rights Commission (AHRC): Lawless law-enforcement and the parody of judiciary in Bangladesh. In Article 2 of the International Covenant on Civil and Political Rights Volume 5. Hong Kong: Asian Human Rights Commission (AHRC); 2006.

13. Cingranelli DL, Richards DL: The Cingranelli-Richards (CIRI) Human Rights Dataset. Binghamton; 2009.

14. Gibney M, Cornett L, Wood R: Political Terror Scale 1 976-2008. 2009.

15. Sethi D, Habibula S, McGee K, Peden M, Bennett S, Hyder AA, Klevens J, Odero W, Suriyawongpaisal P: Guideline for conducting community surveys on injury and violence. Geneva: World Health Organization; 2004: I5I.

16. Wang SJ, Modvig J, Montgomery E: Household exposure to violence and human rights violations in western Bangladesh (I): prevalence, risk factors and consequences. In BMC Int Health Hum Rights Volume 9. Issue I Ecole Polytechnique Federale de Lausanne, EPFL; 2009:29.

17. International Classification of Functioning, Disability and Health (ICF) [http://www.who.int/classifications/icfbrowser/]

18. Norman K, Schutz T, Kemps M, Josef Lubke H, Lochs H, Pirlich M: The Subjective Global Assessment reliably identifies malnutrition-related muscle dysfunction. Clin Nutr 2005, 24(I): I43-I50.

19. Budziareck MB, Pureza Duarte RR, Barbosa-Silva MC: Reference values and determinants for handgrip strength in healthy subjects. Clin Nutr 2008, 27(3):357-362.

20. Hornby ST, Nunes QM, Hillman TE, Stanga Z, Neal KR, Rowlands BJ, Allison SP, Lobo DN: Relationships between structural and functional measures of nutritional status in a normally nourished population. Clin Nutr 2005, 24(3):42I-426.

21. Fess EE: Clinical Assessment Recommendations 2nd edition. Chicago: American Society of Hand Therapists; 1992.

22. Misra A: Revisions of cut-offs of body mass index to define overweight and obesity are needed for the Asian-ethnic groups. Int J Obes Relat Metab Disord 2003, 27(I I): I 294-I 296.

23. Singapore Ministry of Health and Health Promotion Board: Revision of body mass index (BMI) cut-offs in Singapore. Singapore; 2005.

24. Gangopadhyay S, Ghosh T, Das T, Ghoshal G, Das BB: Prevalence of upper limb musculo skeletal disorders among brass metal workers in West Bengal, India. Ind Health 2007, 45(2):365-370. 
25. The Redress Trust: Torture in Bangladesh [97 |-2004. In Making international commitments a reality and providing justice and reparations to victims London: The European initiative for democracy and human rights; 2004:45.

26. Sreeradha D: Political violence in Bangladesh: trends and causes. Strategic Analysis 2005, 29(3):427-447.

27. Mitchell N: Agents of Atrocity New York: Palgrave Macmillan; 2004

28. Perera P: Physical methods of torture and their sequelae: a Sri Lankan perspective. J Forensic Leg Med 2007, I 4(3): | 46-I50.

29. Edston E: Police torture in Bangladesh-allegations by refugees in Sweden. Torture 2005, I 5(I): I6-24.

30. Mariner J: No escape - Male rape in U.S. prisons. New York: Human Rights Watch; 200I.

31. Peel M, Mahtani A, Hinshelwood G, Forrest D: The sexual abuse of men in detention in Sri Lanka. Lancet 2000, 355(9220):2069-2070.

32. Oosterhoff $P$, Zwanikken $P$, Ketting E: Sexual torture of men in Croatia and other conflict situations: an open secret. Reprod Health Matters 2004, I 2(23):68-77.

33. Zawati HM: Impunity or immunity: wartime male rape and sexual torture as a crime against humanity. Torture 2007, I 7(I):27-47.

34. Johnson K, Asher J, Rosborough S, Raja A, Panjabi R, Beadling C, Lawry L: Association of combatant status and sexual violence with health and mental health outcomes in post-conflict Liberia. JAMA 2008, 300(6):676-690.

35. Butler CK, Gluch T, Mitchell N: Security forces and sexual violence: a cross-national analysis of a principal-agent argument. Journal of Peace Research 2007, 44(6):669-686.

36. Alperovitch-Najenson D, Carmeli E, Coleman R, Ring H: Handgrip strength as a diagnostic tool in work-related upper extremity musculoskeletal disorders in women. ScientificWorldjournal 2004, 4: III-II7

37. Mathiowetz V, Kashman N, Volland G, Weber K, Dowe M, Rogers S: Grip and pinch strength: normative data for adults. Arch Phys Med Rehabil 1985, 66(2):69-74.

38. Mathiowetz V, Wiemer DM, Federman SM: Grip and pinch strength: norms for 6- to I9-year-olds. Am J Occup Ther 1986, 40(I0):705-7II

39. Chau N, Petry D, Bourgkard E, Huguenin P, Remy E, Andre JM: Comparison between estimates of hand volume and hand strengths with sex and age with and without anthropometric data in healthy working people. Eur J Epidemiol 1997, I3(3):309-316.

40. Gunther CM, Burger A, Rickert M, Crispin A, Schulz CU: Grip strength in healthy Caucasian adults: reference values. J Hand Surg [Am] 2008, 33(4):558-565.

4I. McDermott MM, Greenland P, Ferrucci L, Criqui MH, Liu K, Sharma L, Chan C, Celic L, Priyanath A, Guralnik JM: Lower extremity performance is associated with daily life physical activity in individuals with and without peripheral arterial disease. I Am Geriatr Soc 2002, 50(2):247-255.

42. Guralnik JM, Ferrucci L, Simonsick EM, Salive ME, Wallace RB: Lower-extremity function in persons over the age of 70 years as a predictor of subsequent disability. N Engl J Med 1995, 332(9):556-56।

43. Shimada $H$, Uchiyama $Y$, Kakurai S: [Relationship between lifestyle activities and physical functions in elderly persons utilizing care facilities]. Nippon Ronen Igakkai Zasshi 2002 39(2): 197-203.

44. Barr EL, Browning C, Lord SR, Menz HB, Kendig H: Foot and leg problems are important determinants of functional status in community dwelling older people. Disabil Rehabil 2005 27(16):917-923.

45. Cattell V: Poor people, poor places, and poor health: the mediating role of social networks and social capital. Soc Sci Med 200I, 52(I0): I50|-15|6.

46. Weare K, Gray G: What works in developing children's emotional and social competence and well-being? Southampton, UK: The Health Education Unit, Research and Graduate School of Education, University of Southampton; 2003:I I5.

47. Schroots J], van Dijkum C, Assink MH: Autobiographical memory from a life span perspective. Int J Aging Hum Dev 2004, 58(I):69-85.

\section{Pre-publication history}

The pre-publication history for this paper can be accessed here:

http://www.biomedcentral.com/1472-698X/9/31/pre pub
Publish with Bio Med Central and every scientist can read your work free of charge

"BioMed Central will be the most significant development for disseminating the results of biomedical research in our lifetime. "

Sir Paul Nurse, Cancer Research UK

Your research papers will be:

- available free of charge to the entire biomedical community

- peer reviewed and published immediately upon acceptance

- cited in PubMed and archived on PubMed Central

- yours - you keep the copyright 